\title{
Homophily and prestige: An assessment of their relative strength to explain link formation in the online climate change debate
}

\author{
Hannah Schmid-Petri (corresponding author) \\ Universität Passau \\ Innstr. 33a \\ 94036 Passau, Germany \\ Hannah.Schmid-Petri@uni-passau.de \\ Silke Adam 1) \\ Ueli Reber1) \\ Thomas Häussler ${ }^{1)}$ \\ 1)Universität Bern \\ Fabrikstrasse 8 \\ 3008 Bern, Switzerland \\ silke.adam@ikmb.unibe.ch, ueli.reber@ikmb.unibe.ch \\ Thomas.haeussler@ikmb.unibe.ch \\ Daniel Maier ${ }^{2)}$ \\ Peter Miltner2) \\ Barbara Pfetsch') \\ 2)FU Berlin \\ Garystr. 55 \\ 14195 Berlin, Germany \\ maier@zedat.fu-berlin.de, miltner@zedat.fu-berlin.de, pfetsch@zedat.fu-berlin.de
}

\author{
Annie Waldherr \\ Universität Münster \\ Bispinghof 9-14 \\ 48143 Münster, Germany \\ Annie.Waldherr@uni-muenster.de
}

Funding:

This publication was created in the context of the Research Unit "Political Communication in the Online World" (1381), subproject 7, which is funded by the DFG, German Research Foundation. The subproject is also funded by the Swiss National Science Foundation (SNF, 100017E-135915).

Version of the article as published in Social Networks, 2018, 55, pp. 47-54 


\begin{abstract}
Previous work has shown that hyperlinks reflect actors' strategic choices; these dyadic relationships depend on the actors' exogenous attributes (e.g., homophily) and the network's endogenous features (e.g., prestige distribution among actors). We combine these factors as explanatory variables in different exponential random graph models (ERGMs) to assess the relative strength of prestige and homophily for the actors' link formation. We analyze the climate change discourse in a hyperlink network formed by US civil society actors from November 2014 and test how relevant the different factors are, including variables such as actor type, country, position, and topic. We find that both prestige and various aspects of homophily influence link formation online. With regard to the importance of the different factors, positional homophily stands out, followed by prestige and other homophily effects.
\end{abstract}

Keywords online network; homophily; prestige; ERGMs; climate change; hyperlink formation

\title{
Highlights
}

- Both prestige and different aspects of homophily influence hyperlink formation

- To have the same position towards an issue is the most important factor

- The second strongest homophily factor is the geographic proximity of actors

- For climate skeptics homophily effects are intertwined with prestige effects 


\section{Homophily and prestige: An assessment of their relative strength to explain link formation in the online climate change debate}

\section{Introduction}

Hyperlinks belong to the basic structural elements of the web (de Maeyer, 2013; Foot et al., 2003; Thelwall, 2006). They structure and organize online communication by connecting different, otherwise isolated, pages and documents (Pilny \& Shumate, 2012). In this way, they guide individuals' surfing paths and serve as relevance indicators for search engines, which find pages that others acknowledge are especially relevant (Hindman et al., 2003; Page et al., 1999). "Links are therefore the roads and signposts of the web but also the currency that measures value online" (González-Bailón, 2009a, p. 272).

Several meanings of links have been discussed in the literature. Depending on the context and on the motivation of the actors setting a link (Ackland \& O'Neil, 2011; Thelwall, 2006), a connection can signal authority (Kleinberg, 1999), trust (Davenport \& Cronin, 2000), support (Park et al., 2004), information exchange (Park et al., 2004), or even criticism (Lusher \& Ackland, 2011). Basically, links can be interpreted as a form of communicative acknowledgment (Pilny \& Shumate, 2012, p. 263; Shumate \& Lipp, 2008). Together, these studies show that links are not set randomly, but instead they reflect the strategic choices of the actors involved (González-Bailón, 2009a; Park, 2003; Tremayne, 2004).

These strategic choices seem to depend on the dyadic relation between two actors as well as on the overall structural features of the network. From a purely dyadic perspective, homophily has been identified as a driving force for link formation (e.g., Ackland \& Shorish, 2014; Ackland \& O’Neil, 2011; Fu \& Shumate, 2016). Homophily means that actors tend to link to those who share similar attributes such as the same language, the same topics, or similar political preferences. Concurrently, from the viewpoint of the overall structure of a network, research has shown that link formation is driven by prestige, resulting in some actors becoming central authorities because they receive more links (González-Bailón \& Wang, 2016; O’Neil \& Ackland, 2006; Shumate \& Lipp, 2008).

In this article, we aim to arrive at a fuller understanding of link formation processes by combining these two perspectives. In our study we use the online discussion about climate change as an example. This case is very suitable to study link formation processes driven by prestige and/or homophily as it is an issue in which contrasting positions are voiced and in which actors from different regions and of varying types are included (Elgesem et al., 2015; Elgin, 2015). Thus, our work addresses the following research question: How important are various aspects of homophily and prestige in explaining link formation regarding climate change on the web? 
Our study contributes to research on link formation in a fourfold manner. First, we go beyond research that focuses on specific aspects of link formation, integrating prestige and homophily into a single model; this allows us to assess their relative strength vis-àvis each other. Second, there has been little research comparing different forms of homophily regarding their explanatory power, and we therefore include homophily as a multifaceted concept. Additionally, as only little research (Ackland \& O'Neil, 2011; González-Bailón, 2009a) has asked whether homophily regarding the topics discussed on websites triggers link formation, we pay special attention to measuring content similarity. Third, we go beyond existing analyses of how positions impact hyperlink behavior, as we not only look for increased linking among like-minded (homophily) or differently minded (heterophily) people, but we also search for purposeful avoidance behavior to abstain from linking to those with opposing views; we include these avoidance mechanisms to explain link formation. Fourth, we combine homophily and prestige in a nested model to gain deeper insights into possible interaction effects between the two factors.

Understanding these mechanisms is important, as linking patterns determine which actors, topics, and ideologies gain visibility in digital public spheres. Therefore, we must gain a deeper knowledge of the networking behavior of individuals and organizations as well as uncover the strategies that online activists use to spread their ideas. Link formation is closely connected to creating new power structures: "the pattern of network ties can be revealing about the processes that give rise to them" (Lusher, Koskinen, \& Robins, 2013, p. 18). At the same time, the actors' orientation toward similar "others" might be apt to undermine the integration of the digital spacewhether the combined effect of homophily and prestige contributes to further eroding or expanding the public sphere remains an open question.

To answer our research question, we analyze the climate change discourse in a hyperlink network formed by US civil society actors from November 2014. Focusing on an online network created by actors belonging to civil society seems particularly relevant, as the web offers those who are often seen as "weak" actors in public discourse formed by traditional media new ways to form alliances, mobilize for their campaigns, share information, and influence public opinion (Benkler et al., 2015; Elgin, 2015).

\section{Explanation of hyperlink formation on the web}

In general, link formation has been explained by two different approaches: the instrumental use of hyperlinks and the more symbolic, identity-building use of hyperlinks (Ackland \& O’Neil, 2011; Baldassari \& Diani, 2007; González-Bailón, 2009a). From an instrumental perspective, links provide access to resources that are needed to achieve certain goals online. The most important resource online is the visibility of websites as measured by search engines (e.g., Google's page rank algorithm), which essentially allocate them different gradations of importance and hence prestige. One of the most important factors contributing to prestige online is the number of incoming 
links from other actors that are themselves prestigious in terms of their visibility. Most of the search engine algorithms assume that the more inlinks a website receives, the more important and influential the site is (González-Bailón, 2009a, p. 272; Brin \& Page, 1998) because they see an inlink as acknowledging the relevance of a website (Gibson et al., 1998; Park, 2003). From previous research, we know that online networks are highly centralized (González-Bailón \& Wang, 2016). In other words, a small number of nodes command most of the prestige, followed by a long tail of less important actors (Barabasí \& Albert, 1999). This power law principle seems to sustain itself on the web: research has shown that those who already receive many inlinks seem to gain more links in the future, a process called "preferential attachment" (Barabasí \& Albert, 1999; Lusher et al., 2013, p. 17). As a result, centralization tendencies increase (the rich get richer phenomenon of the web as described by Barabási et al., 2000; see also McNutt \& Marchildon, 2009). Thus, to link to actors with many inlinks demonstrates recognition of these actors' importance in a specific field, and it may in turn help the "linker" to gain more traffic or a higher visibility for its own website (Ackland \& O'Neil, 2011; Marlow, 2004). Interestingly, prestige in the online world seems to be connected to prestige in the offline world. For example, González-Bailón (2009a, 2009b) shows that visibility in traditional media or extensive financial resources positively correlate with organizations' prestige in online networks.

Turning to the symbolic perspective of hyperlink setting, research has shown that actors link to similar others based on common values, interests, geographical areas, or organizational routines. In such a setting, hyperlinks between certain groups of actors may support the development of a collective identity and a sense of "we-ness" (Ackland \& O’Neil, 2011; Pilny \& Shumate, 2012). This "selection of others that are similar" (Monge \& Contractor, 2003, p. 223) is a well-studied linking principle in (online) social networks falling under the term homophily (McPherson et al., 2001), meaning "that contact between similar entities occurs at a higher rate than among dissimilar entities" (Atouba \& Shumate, 2015, p. 588; Kossinets \& Watts, 2009). We adapt Atouba and Shumate's (2015, p. 589) work, distinguishing two basic types of homophily: attributebased homophily (1) and institutional homophily (2).

Attribute-based homophily means that actors link to each other based on general characteristics and information about certain actor attributes. For example, previous work has shown higher linking activity between actors belonging to the same actor type (1a). Rogers and Marres (2000) demonstrate that non-governmental organizations (NGOs) tend to link to other NGOs, while Kaiser et al. (2016) and Elgin (2015) only find this mechanism at work between political actors. Beside the actor type, the (political) position also has an influence on linking behavior (1b): Several studies on political blogs show that conservative bloggers are much more likely to link to other conservative blogs and liberal bloggers to other liberal blogs (Ackland, 2005; Adamic \& Glance, 2005; Hargittai et al., 2008). For the discussion about climate change, Elgin (2015) demonstrates that for those actors who follow the scientific consensus on climate change, homophily is more important in their linking behavior (i.e., they tend to link to 
other climate advocates) than it is for skeptical actors (those who question the scientific consensus); their linking behavior is more diverse and also includes cross-camp linking. A third type of attribute-based homophily refers to discussing the same issues by respectively pursuing the same interests (1c). Ackland and O'Neil (2011) confirm homophily for different environmental submovements according to the field of activity, which they identify through the use of similar meta-keywords on their websites. This result is corroborated by other studies, which have demonstrated that the same area of interest, similar goals, or joint projects lead groups of civil society actors to link to each other (Bae \& Choi, 2000; González-Bailón, 2009a; Lusher \& Ackland, 2011; Pilny \& Shumate, 2012). Fourth, actors belonging to the same social, cultural, or geographical environment (1d) tend to link to each other. Shumate and Dewitt (2008) point out that NGOs from the same continent are more likely to link to each other. Rogers and BenDavid (2008) show that, especially for Israeli organizations, they more often link to other Israeli NGOs and less often to actors from outside of Israel.

Atouba and Shumate (2015) describe institutional homophily as a second type of homophily: the tendency that two organizations are more likely to cooperate (or link to each other) when they have a common partner such as a common funder, a common institutional convener, or a common legal registration (see also Fu \& Shumate, 2016). This idea is based on the structural enhancement of Heider's balance theory that tries to explain group formation in social networks and that basically states that social actors try to balance their affective ties in triads (e.g., Hummon \& Doreian, 2003). For social networks, this means concretely that it is probable that "a friend of my friend as well as an enemy of my enemy is my friend" (Antal, Krapivsky \& Redner, 2006, p. 130). Accordingly, a link between two nodes is more likely if they both link to a third node (a triad). The formation of such a triad is the result of a dual process: a similar choice of partners and a shared network activity. Robins et al. (2009, p. 106) term this kind of homophily 'activity-based structural homophily'.

To sum up, the state of research clearly points to three explicative factors for link formation: prestige, attribute-based homophily, and institutional homophily. With regard to previous research, we identify two main desiderata. First, concerning homophily, existing studies report that actors tend to form relationships with likeminded others; in the political context, this is often associated with the development of echo chambers or filter bubbles (Sunstein, 2001) and also study the linking behaviour between opposing camps (i.e., heterophily effects) (e.g., Hargittai et al., 2008; Elgin, 2015). Previous studies often neglect, however, to control whether it is actually reasonable to speak of positional homophily or heterophily, or whether it would be more correct to speak of avoidance effects, meaning that actors' linking behavior is less driven by a focus on within- or between-camp linking but more by their desire to ignore the opponent side. Second, despite the fact that several studies test single aspects of prestige or homophily separately, there has been little research comparing the relative importance of different aspects regarding their explanatory power or how they interact. An exception is the study by González-Bailón (2009a), who demonstrates that the same 
field of activity has a greater explanatory power for the connection between two NGO websites than does prestige.

Our first research goal is to assess the general importance of prestige and homophily. We expect that both prestige and homophily contribute to understanding the topology of a hyperlink network. Additionally, we go into more detail and compare the relevance of prestige and different aspects of homophily regarding their explanatory power. Our second goal is to test for avoidance effects as the flipside of homophily. The general linking logic of homophily and prestige might not be as separate as it is treated in the literature-it might well be that both mechanisms are closely intertwined in that actors link, for example, only to prestigious like-minded actors. Thus, our third research goal is to combine these different factors and search for nested mechanisms of link formation.

\section{Research design, methods, and measurement}

\subsection{Research design: Hyperlink networks of challenger actors}

We chose the online discussion about climate change induced by US actors to answer our research question. This case is especially suitable, as the discourse about climate change includes various highly active actor types online (Elgesem et al., 2015; Elgin, 2015; Kaiser et al., 2016). Additionally, climate change-especially in the US-includes two opposing positions, with "advocates" who believe that man-made global warming exists and perceive it as problematic on the one side, and climate "skeptics" who neglect the occurrence or the human contribution to the changing climate on the other side (e.g., Dunlap \& McCright, 2011). Thus, there are opposing positions online, but also different aspects in the discussion of the issue (e.g., causes of climate change, consequences of climate change, political goals) that might have the potential to bind different groups of actors together (e.g., Elgesem et al., 2015). Additionally, climate change is a global issue that is debated among actors from different countries (Roger \& Marres, 2000). It is a salient issue in public discourse that is vividly discussed online by various actors who emphasize distinct aspects of the issue and pursue different goals. Therefore, the issue constitutes an especially suitable case to study linking behavior online.

We used a five-step process to generate the online hyperlink network. First, we identified the most prominent challenger actors in our issue field using literature reviews, expert interviews, and country-specific Google searches with deleted search histories employing appropriate keywords. ${ }^{1}$ We used "climate change" and "global warming", widely used as appropriate terms in the research on climate change (e.g., Painter \& Gavin, 2015; Shapiro \& Park, 2015), as keywords to define the issue and the actors involved in it.

\footnotetext{
1 "Climate change" or "global warming."
} 
Following Kriesi (2004, p. 189), we defined challengers as political outsiders who pursue a specific political goal but have no institutionalized access to formal political institutions (e.g., civil society organizations, but also bloggers and universities or research institutes). We used the four most prominent national climate advocates and the four most prominent national climate skeptics (respectively, a page on each actor's website that refers to climate change), as determined by literature reviews and Google searches, as seeds for a web crawler (see Appendix A). The seeds were restricted to four on each side as this ensures that they all commanded comparable levels of visibility and presence in the debate. Seeds belong to national branches of large NGOs (e.g., Greenpeace, World Wildlife Fund) as well as more country-specific organizations and think tanks (e.g., Worldwatch Institute, Heartland Institute) and prominent blogs (e.g., Watts Up With That, C3 Headlines). Our pretests showed that the seeds captured the main currents of the debate occurring on the web.

Second, we used the crawler software Issue Crawler (govcom.org, 2014) to collect the network - one of the crawlers that is most commonly used in social science research (Ackland, 2013, pp. 86-90). We set the crawler to start from the seed pages, follow hyperlinks two levels deep in order to collect internal links within the respective website, and then collect all outgoing links from the fetched web pages directed to external websites. In a final iteration, the crawler checked all of the websites identified in the first step for links that run between them. The crawl took place on November $5^{\text {th }}$, $2014^{2}$. Pre-tests showed that choosing a wider boundary specification resulted in substantially more 'noise', that is, actors who are not part of the debate on climate change. ${ }^{3}$

The crawler follows all hyperlinks regardless of website content, so we applied an additional filtering procedure as a third step and automatically indexed all of the web content with the original set of keywords, excluding all web pages that did not contain one of the keywords ${ }^{4}$ at least once. This resulted in a reduced network in which all of the actors engaged in different aspects of the discussion about climate change (for a similar approach, see Waldherr et al., 2017). We also excluded social networking sites (e.g., Facebook and Twitter), as they are online platforms rather than actors in the issue. This resulted in a network with 574 nodes and 2,106 edges.

Fourth, we extracted the network formed by challengers in this network (in this way, all of the challengers and the links between them were included in the network). Furthermore, as the crawler follows all links regardless of their target, the network analyzed here represents the online discussion about climate change generated by but not limited to US civil society actors. We focused on challengers because their linking

\footnotetext{
2 The exact start date was von 4 a.m. on 5/11/2014 and the end date on 10 a.m. on 5/11/2014

${ }^{3}$ While the original networks already contained a degree of 'noise' often approaching $60 \%$, extending the boundary to two iterations increased it to over $80 \%$.

4 "Climate change" or "global warming."
} 
behavior has been shown to be more active and diversified than that of other actor types (Ackland \& O'Neil, 2011; Rogers \& Marres, 2000), and their communication patterns are therefore more likely to reflect the existing alliance structures that shape the climate change issue. Additionally, these "weak" actors in public discourse especially benefit from the easy-access and low-cost nature of online communication when mobilizing supporters and transmitting their ideas and goals (Elgin, 2015). Schäfer (2012, p. 530) describes civil society organizations engaged in environmental issues as "the champions of online communication."

Fifth, we extracted the largest connected graph and reduced our network further to include only those challengers with a minimum degree of two links (out of which at least one is an indegree). This ensured that all of the actors in the network were recognized by at least one other actor as being part of the debate. It also makes the network structure less depended on the activity of the seeds and ensures that what we capture is the mainstream of the debate. We then dichotomized the network: a connection between two nodes $i$ and $j$ was either present (1) or not (0). We excluded loops. This resulted in a network with 207 nodes, 1,283 edges, and a density of .03.

\subsection{Measurement of prestige and homophily}

To evaluate prestige we looked at the indegree of each node by counting all incoming links per node. This is a measurement of prestige that has often been used in previous studies (González-Bailón, 2009a, 2009b; Marlow, 2004). As the indegree distribution in our network was highly skewed and followed the classical long tail distribution, we used the square root of the indegree (see Snijders et al., 2010 for a similar approach).

To measure attribute-based homophily, we classified actors in the network based on the contents on their websites by using manual and automated content analysis techniques. First, we relied on manual coding to differentiate between different actor types within the challenger network: we distinguished between civil society organizations such as social movement organizations (SMOs) and non-governmental organizations (NGOs) (6\%), universities/research institutes (12\%), and individual activists (mainly bloggers, $83 \%)$. Second, we manually coded each actor's position on climate change and classified our actors into either climate advocates (following the scientific consensus represented by the Intergovernmental Panel on Climate Change (IPCC); 19\%), climate skeptics $(77 \%)$, or not identifiable (3\%). "Skeptical" in this context was defined as denying the occurrence of climate change, the man-made contribution to it, its detrimental consequences, or opposing corresponding policy proposals and regulations. We only identified an actor as being a skeptic if a clear statement concerning human-induced climate change was found on the website. Third, to measure geographical homophily, we manually coded the geographic area where the actor was most active (USA: $48 \%$, UK: 15\%, Australia: 11\%, Canada: 7\%, New Zealand: 2\%, Norway: 2\%, transnational/international actors: 4\%, other/unknown: 10\%). Two trained coders conducted the coding (Krippendorff's alpha $=.91$ ). 
Fourth, we used latent Dirichlet allocation (LDA) topic modeling to measure topic similarity among actors; this was an unsupervised approach of automated content analysis on a corpus of 3,415 web pages. LDA is a generative probabilistic model that can be used to describe latent thematic structures in a collection of documents (Blei, 2012). Documents are seen as mixtures of latent topics, where each topic is characterized by a distribution over words (Blei et al., 2003, p. 996; see also Maier et al., 2017a). Topics are thus abstract patterns of words that frequently occur together. The number of topics has to be specified in advance in order to run the LDA. As for our research question, there is little theoretical guidance on how many topics describe the online discussion about climate change appropriately, so we used a mixture of a datadriven approach and a qualitative assessment of the interpretability of different solutions with various numbers of topics. We validated and interpreted the topics in a multistage process to make sense of their semantic meaning (for a more detailed description, see Maier et al., 2017b). Finally, a model with 40 topics provided us with a manageable number of topics while maintaining enough detail to describe the online discussion about climate change. Out of these 40 topics, we removed 14 uninterpretable "boiler plate" topics. In order to identify the aspect of the climate change debate an actor is most concerned about, we clustered the remaining 26 topics based on the JensenShannon divergence of their word probability distributions (Niekler \& Jähnichen, 2012, p. 319) using hierarchical clustering (Ward's method). Thus, we aggregated the 26 topics into 11 topic clusters (see Appendix B). For the analysis, we identified the most prominent topic cluster for each actor, which we defined as the cluster with the highest average proportion of overall documents on the actor's website.

Finally, we measured institutional homophily through the occurrence of transitive triads-that is, local linking patterns where two nodes $i$ and $j$ link to a third node $k$, in which a tie between $i$ and $j$ exists (Holland \& Leinhardt, 1976). In line with Atouba and Shumate's (2015) definition of institutional homophily, we assumed that the relation between the two nodes did not have to be mutual. In contrast to the measurement applied by Atouba and Shumate, the two nodes $i$ and $j$ did not have to belong to the same actor type. As online communication includes a broad variety of different actor types that are free to connect to each other, we adapted their original conceptualization to this new communication realm and allowed diverse actor types for $i$ and $j$.

\subsection{Exponential random graph models}

To determine which factors drive hyperlink formation in the network, we rely on Exponential Random Graph models (ERGMs) using the xergm-package (version 3.7.1; Leifeld, Cranmer \& Desmarais, 2017) for the statistical software R (version 3.3.2). ERGMs are statistical models that can be used for analyzing the structure of empirical networks. The major advantage of the ERGM framework is that potential dependencies among the relational observations are taken into account (Cranmer et al., 2012). Thus, ERGMs may be used to analyze and explain which factors influence the presence or absence of a link in a network (Lusher et al., 2013). Thus, "with an ERGM, we predict[ed] 
the presence of a network tie (a binary variable) from several predictor variables" (Lusher et al., 2013, p. 34; see also Shumate \& Palazzolo, 2010). Two types of predictors can be included and estimated in an ERGM: (endogenous) structural and (exogenous) attribute effects.

On the structural level, we included the measure for institutional homophily (triad 030T). Furthermore, we controlled for variables that are common for online networks in general and that were proven relevant in network descriptives and goodness-of-fit measures for our networks, including the mutuality of links, geometrically dyad-wiseshared partners, indegree $=1$, and the square root of the outdegree (e.g., Lusher et al., 2013, p. 17; Robins et al., 2007; 2009). Turning to the attribute effects, we included our measurement for prestige (the square root of the indegree) and also looked at how strongly link setting was determined by our different types of attribute-based homophily-namely, homophily regarding actor type, position, geographical region, and issue focus.

We conducted three different ERGMs for the analysis. All of the models successfully converged and fitted the data well (see Appendix C for goodness-of-fit statistics). In Model 1, we tested our basic assumptions about the influence of prestige and different aspects of homophily. Models 2 and 3 focused in more detail on the most debated aspect of homophily research: the role of linking among like-minded actors, for which many see the risk of emerging cyberspace fragmentation. Model 2 served as a control for the estimated positional homophily effects; we checked for positional avoidance effects. Model 3 was concerned with the so-far-assumed independence of prestige and positional homophily effects. Here, we searched for nested relationships of our independent variables; we tested whether linking among like-minded actors only referred to prestigious actors or whether avoidance effects were weakened if considering cross-camp linking among prestigious actors. To test for nested effects, we divided our network into prestigious nodes (i.e., nodes that receive many inlinks, or "authorities") and the long tail of nodes with less inlinks. Based on the indegree distribution, we used the elbow criterion to divide the nodes, resulting in 46 authorities (i.e., nodes with 8 or more inlinks) and 161 nodes located in the long tail of the distribution. In sum, the authorities received $67 \%$ of all inlinks $(n=1,283)$. We then combined this measurement of prestige with the position concerning climate change and divided our network into four categories: skeptical authorities (19\%), alarmist authorities (2\%), nodes belonging to the alarmist (17\%), and skeptical long tail (58\%; not identifiable: $3 \%$ ).

\section{Results}

With regard to the structural parameters (see Table 1), all three models reveal that mutual relationships are more likely than we expected in a random network, meaning that reciprocal hyperlinking behavior seems to be a common practice in our network. In contrast, multiple two paths (geometrically weighted dyadwise shared partners) are a 
structure that is not more likely to occur than in a ceteris paribus-specified random network. Combined with the finding that many nodes receive only one inlink, this may point us to a common structure of online issue networks: Many websites only receive one link; hence, online connectivity often ends after one step and does not include more complex path structures. The significant estimate of the outdegree popularity shows that there are some very active nodes in the network regarding their outlinking behavior.

Concerning the importance of prestige and different aspects of homophily, the first model shows that, in our case, prestige is a fundamental attribute for explaining link formation online. Regarding homophily, the results show various significant effects for different aspects. Thus, as a first result we can state that, both prestige and different aspects of homophily influence link formation in our network. With regard to the relative importance of the different factors, positional homophily stands out, followed by prestige and the other homophily factors.

When we take a closer look at the effects of different facets of prestige, our results show that the network is highly centralized, with a few very prestigious nodes. Furthermore, there is a tendency toward preferential attachment, meaning that for nodes that already have many inlinks, it is probable that they will receive even more in the future. The top 10 most prestigious nodes are mainly skeptical bloggers such as Watts Up With That?, JoNova, JunkScience, or Tom Nelson's Blog.

Finally, for our network, the different aspects of homophily vary greatly in explaining link formation. Here, it becomes obvious that positional homophily has the strongest positive effect on link formation, particularly among climate advocates. Surprisingly, the second strongest homophily factor is the geographic proximity of actors. There are two other homophily factors that are significant but relatively weak: First, homophily concerning the topics is only significant for two topic clusters, in which politics and elections ${ }^{5}$ and different climate change research institutions and its members are discussed (and in the latter case also criticized). Additionally we can state based on our data, that these are topics which are prominently used by skeptical actors.

Second, institutional homophily is only of marginal, albeit significant, importance. In contrast, homophily concerning the actor type has no significant influence at all on link formation.

We include avoidance relations in our model to determine whether it is correct to say that our networks are determined by positional within-camp linking (homophily) or are driven by the avoidance of cross-camp linking. Model 2 (Table 1, second column) shows that for climate advocates, the strong homophily relationship persists, whereas for climate skeptics, the homophily effect is no longer significant. Instead, climate-skeptical link formation is driven by relationships across the political divide that occur to a

${ }^{5}$ This cluster includes a discussion about the US election and about Australian climate politics. 
significantly lower degree than expected; similarly, advocates avoid building ties with skeptics.

Our third model is concerned with the possible interdependence of homophily and prestige; here, we searched for nested relations (Table 1, third column). To do so, we divided our sample into four different groups (see above) and tested the impact of the different combinations. ${ }^{6}$ Various nested effects may be possible: First, prestige might be such an influential factor that we even find cross-camp linking to prestigious actors belonging to the opposing camp. However, table 1 (third column) shows that this kind of interaction effect does not occur in our network. Second, nested effects may structure within-camp linking meaning that actors prefer to link to prestigious actors which hold the same position. As can be seen in table 1 our third model reveals, that this nested effect is for both camps (skeptics and advocates) significant. But, compared to the influence of prestige or positional homophily our results show that for skeptics the nested effect is more important than the mere egalitarian positional homophily effect (skeptical long tail to skeptical long tail or skeptical authority to skeptical authority). In contrast, climate advocates show significant linking behavior to all members of the same camp - independently of their prestige.

Thus, to sum up, based on our results it seems that for skeptics the prestige another skeptical actor has online is an important driver for their linking behavior. They tend to link more to their skeptical authorities. In contrast advocates' within-camp linking behavior is not so dependent on prestige considerations, and in this view, more egalitarian.

6 Three possible combinations were excluded because of too-small case numbers. 
Table 1: Exponential random graph models (ERGMs)

\begin{tabular}{lccc}
\hline & Model 1 & Model 2 & Model 3 \\
\hline Edges & $-8.96(.16)^{* * *}$ & $-8.27(.20)^{* * *}$ & $-8.60(.19)^{* * *}$ \\
\hline Structural mechanisms & & & \\
& & & \\
\hline Mutual & $2.06(.16)^{* * *}$ & $1.99(.16)^{* * *}$ & $2.27(.17)^{* * *}$ \\
\hline Gwdsp (alpha $=0.5)$ & $-.02(.00)^{* * *}$ & $-.02(.00)^{* * *}$ &,$- 02(.00)^{* * *}$ \\
\hline Indegree = 1 & $.85(.21)^{* * *}$ & $.85(.21)^{* * *}$ & $.71(.21)^{* * *}$ \\
\hline Outdegree (square root) & $.77(.02)^{* * *}$ & $.76(.02)^{* * *}$ & $.76(.02)^{* * *}$ \\
\hline
\end{tabular}

Prestige

\begin{tabular}{clll}
\hline Indegree (square root) & $.79(.02)^{* * *}$ & $.79(.02)^{* * *}$ & $.71(.03)^{* * *}$ \\
\hline
\end{tabular}

Homophily mechanisms

\begin{tabular}{llll}
\hline Institutional homophily & $.06(.01)^{* * *}$ & $.06(.01)^{* * *}$ & $.07(.01)^{* * *}$ \\
\hline Position: skeptic & $.73(.10)^{* * *}$ & $-.00(.16)$ & \\
\hline Position: advocate & $2.99(.16)^{* * *}$ & $2.27(.20)^{* * *}$ & \\
\hline Actor type: Org./NGOs/SMOs & & & \\
\hline Actor type: universities/research inst. & $.34(.29)$ & $.38(.29)$ & $.41(.29)$ \\
\hline Actor type: Blogger & $.08(.08)$ & $.13(.08)$ & $.08(.08)$ \\
\hline Country: US & $.23(.07)^{* *}$ & $.25(.08)^{* * *}$ & $.24(.07)^{* *}$ \\
\hline Country: UK & $.88(.18)^{* * *}$ & $.89(.18)^{* * *}$ & $.87(.18)^{* * *}$ \\
\hline Country: Australia & $.79(.21)^{* * *}$ & $.85(.22)^{* * *}$ & $.82(.22)^{* * *}$ \\
\hline Country: Canada & $.82(.36)^{*}$ & $.85(.36)^{*}$ & $.82(.36)^{* *}$ \\
\hline Topic: politics \& elections & $.85(.39)^{*}$ & $.87(.39)^{*}$ & $.80(.40)^{*}$ \\
\hline Topic: climate regulation & $1.43(.75)$ & $1.48(.75)^{*}$ & $1.34(.77)$ \\
\hline Topic: economic/energy policy & $.01(.58)$ & $.00(.58)$ & $-.01(.58)$ \\
\hline $\begin{array}{l}\text { Topic: discussing the occurrence of } \\
\text { climate change }\end{array}$ & $.31(.62)$ & $.23(.62)$ & $.23(.60)$ \\
\hline & & & \\
\hline
\end{tabular}




\begin{tabular}{|c|c|c|c|}
\hline Topic: temperature \& weather changes & $-.05(.09)$ & $-.01(.09)$ & $-.02(.09)$ \\
\hline $\begin{array}{l}\text { Topic: (discussing) causes/ } \\
\text { explanations of climate change }\end{array}$ & $.23(.42)$ & $.21(.42)$ & $.21(.42)$ \\
\hline Topic: questioning climate science & $.08(.33)$ & $.11(.33)$ & $.06(.33)$ \\
\hline $\begin{array}{l}\text { Topic: (criticism of) climate change } \\
\text { research institutions and members }\end{array}$ & $.41(.20)^{*}$ & $.45(.20)^{*}$ & $.41(.20)^{*}$ \\
\hline \multicolumn{4}{|l|}{ Avoidance mechanisms } \\
\hline Position: skeptic-advocate & & $-.78(.20)^{* * *}$ & \\
\hline Position: advocate-skeptic & & $-1.31(.25)^{* * *}$ & \\
\hline \multicolumn{4}{|l|}{ Nested effects (prestige and position) } \\
\hline Skeptical authority - skept. authority & & & $.48(.15)^{* *}$ \\
\hline Skeptical authority - skept. long tail & & & $.35(.16)$ \\
\hline Skeptical authority - advoc. long tail & & & $-.04(.25)$ \\
\hline Advocate authority - advoc. authority & & & $3.32(.50)^{* * *}$ \\
\hline Advocate authority - advoc. long tail & & & $2.34(.43)^{* * *}$ \\
\hline Advocate authority - skept. long tail & & & $.83(.60)$ \\
\hline Skeptical long tail - skept. authority & & & $.94(.15)^{* * *}$ \\
\hline Skeptical long tail - advoc. authority & & & $-.32(.36)$ \\
\hline Skeptical long tail - skept. long tail & & & $.27(.16)$ \\
\hline Advocate long tail - skept. authority & & & $-.55(.28)$ \\
\hline Advocate long tail - advoc. authority & & & $3.32(.26)^{* * *}$ \\
\hline Advocate long tail - advoc. long tail & & & $2.43(.23)^{* * *}$ \\
\hline Advocate long tail - skept. long tail & & & $-.58(.47)$ \\
\hline AIC & 6628.86 & 6602.97 & 6596.36 \\
\hline BIC & 6836.71 & 6828.14 & 6899.48 \\
\hline Log likelihood & -3290.43 & -3275.48 & -3263.18 \\
\hline
\end{tabular}




\section{Discussion}

The aim of our study was to gain deeper insight into how to explain link formation in an online issue network comprised of civil society actors discussing climate change. We derived three main research goals based on the previous research and its resulting desiderata. First, we wanted to assess the general importance of prestige and homophily for link formation in our network. We intended to compare the relevance of prestige with different aspects of homophily. Second, we wanted to test for avoidance effects concerning positional homophily. Third, we combined homophily and prestige and searched for nested effects to explain the connection between two actors in our network.

The results of our study show that it is not sufficient to individually study prestige or homophily in order to understand link formation, as separate models run the risk of overestimating their effects. In our study, it is clear that prestige, as well as different forms of homophily, drive link formation, with positional homophily being the single most important factor. With regard to prestige, the issue network is highly centralized with some very important and central actors. Among the most prestigious nodes are skeptical bloggers, who neglect the occurrence of anthropogenic climate change or its negative impacts. Thus, we find evidence that, in the online discussion about climate change, bloggers serve as the new "authorities" instead of universities or research institutes that have traditionally held the highest prestige in debates about sciencebased issues. This adds a new aspect to previous studies that analyzed the relationship between offline and online prestige: unlike media visibility or financial resources (González-Bailón, 2009a, 2009b), a good scientific reputation in the offline world does not necessarily lead to visibility and prestige online.

Positional homophily, however, turned out to be a dualistic concept; linking is not only driven by an actor's tendency to prefer those who hold the same position as him or herself, but also by the avoidance of connections to the other side. This aspect has been mostly neglected in previous studies (for an exception, see Elgin, 2015) and should be considered more extensively in future research.

Regarding the online climate change discourse based in US civil society, our hyperlink network is fragmented along the boundaries between different positions. Climate change advocates seem to form echo chambers (Sunstein, 2001) in the fullest sense: not only do they prefer linking within their own camp, but they also tend toward forming a strong demarcation from the skeptical side. Their linking behavior reflects the symbolic purpose of setting hyperlinks: forming a collective identity online, and creating a feeling of "we-ness." Interestingly, the skeptics also contribute to online fragmentationalthough their linking behavior supports their own camp to a lesser degree, they also show tendencies to avoid cross-camp linking. That the effects of homophily among advocates are more pronounced, compared to their skeptical counterparts, might reflect the larger political context (González-Bailón \& Wang, 2016; Häussler et al., 2017). Advocates still constitute a majority (although skeptics seem to be gaining ground, 
especially in the US) and their position is additionally bolstered by a widely acknowledged scientific consensus regarding man-made climate change. Thus, they try to exclude skeptical viewpoints from their online discourse, have no reason to discuss the minority position or make skeptical arguments prominent, and they strategically isolate themselves from other viewpoints (Collins, 2014). In contrast, skeptics still form a minority that opposes the widely acknowledged scientific consensus (e.g. Anderegg, 2010; Cook et al. 2013). As such, they need to become more strongly involved with the mainstream debate.

Our study also reveals that positional homophily and prestige effects are not always as independent as has often been assumed. Our results show that nested effects between prestige and homophily exist for both camps. However, compared to positional homophily, for climate change advocates, standing on the same side of the conflict is more important than the prestige of a node, which underlines the importance of positional effects. In contrast, for skeptics, the nested effect is more important than the mere positional effect.

This might reflect how the climate change discourse within the camps and across them is organized. Despite differing opinions and approaches on how to combat climate change, the advocate side of the debate is united by a common awareness of its causes and a recognition of its harmful effects. Here, political bodies, scientific institutions, and NGOs largely agree on the projections of climate change trends, and hence promote similar conceptions of how to address them. This is a discourse that essentially seeks to couple the existing mainstream scientific knowledge with action-political, economic, social, or otherwise. The mobilizing, lobbying, and cooperative efforts of the actors are mirrored in the lack of hierarchy on this side of the debate.

Cooperation also characterizes the other, skeptical side, but in a different way. As skeptics dispute the causes and/or consequences of climate change, their discourse operates outside the common scientific understanding and they therefore rely on a select few actors, who broker the debate, generate counterarguments, and provide a platform for their views. Thus, their linking behavior makes their own authorities prominent, whereas the long tail remains invisible and helps to make climate skeptics the most visible actors in the networks analyzed (see also anoymized).

Finally, going beyond positional homophily and prestige, there is one additional factor that explains link formation: living in the same country. This points to the fact that online communication is not as global as is often assumed (for similar results, see Barnett \& Park, 2005; Park et al., 2011). An explanation for this result might be that although climate change is a potentially transnational issue, policies to mitigate climate change have to be discussed and implemented at the national level. It is also a plausible assumption that actors primarily link to other actors whom they know also from other (real-life) contexts-a behavior that also favors actors living in the same country. 
Interestingly, the three remaining homophily mechanisms, institutional homophily, topic similarity, and actor-type homophily, have proven to be of less importance in explaining link formation in the climate change network that we analyzed.

At least two strands for future research have emerged from our study. First, more research needs to compare and explain the variations between the strategic linking behavior of the different camps. While our study shows that advocates' linking behavior is more internally focused, yet less hierarchical, compared to that of skeptics, we still lack a systematic explanation for this phenomenon. Second, we have to keep in mind that our network data was collected in 2014; it would be interesting to collect similar data today, as climate skeptics now have, with the election of Donald Trump, a powerful political representative, a phenomenon that might change their strategic linking behavior.

Our study is not without limitations. We only tested our assumptions for one network dealing with one specific issue (climate change) and generated in a specific country (the US). Thus, the question arises of how generalizable our results are. Climate change can be characterized as a positional issue with clear-cut policy positions. For this type of issue, we find that positional homophily explains the connection between different actors. We assume that this result is transferable to other countries where actors take different positions on a given issue. For valence issues that incorporate less clear positions, the position may be less important. Perhaps in this case, homophily concerning the topics or interests discussed on a particular site becomes more important-but this is a question for future studies.

We restricted our network to challenger actors based in civil society, as they profit the most from the advantages of online communication and can be seen as its champions (Schäfer, 2012). Future research should test how the observed processes work for other actor types such as established political actors. Furthermore, we tried to transfer Atouba and Shumate's (2015) conceptualization of institutional homophily to the structural features of an online network. There might be other ways of measuring institutional homophily, as our models only show small effects for it. Future researchers should apply and test further measurements of this factor in an online hyperlink network. Finally, one caveat of our study is also that we have not looked at social media. However, as actors are active on all venues, also such a partial approach is helpful in revealing the characteristics in linking practices (see for a similar argument Benkler et al. 2013).

In conclusion, our study shows that an actor's position concerning an issue plays a crucial role in the setting of a hyperlink. This illustrates that hyperlinks reflect strategic choices from the actors involved and are not set randomly. Together with the importance of prestige, it appears that who an actor is becomes more important than what topic the actor is talking about in terms of receiving or setting a hyperlink. 


\section{APPENDIX}

\section{A. Source seeds}

Skeptics:

- http://heartland.org/issues/environment

- http://wattsupwiththat.com

- http://www.c3headlines.com

- http://www.climatedepot.com

Advocates:

- http://www.climatecentral.org

- http://www.greenpeace.org/usa/en/campaigns/global-warming-and-energy

- http://www.worldwatch.org/climate-energy

- http://www.worldwildlife.org/climate/index.html

\section{B. topics}

\begin{tabular}{|c|c|c|c|c|}
\hline topic & top words & \multicolumn{2}{|c|}{ cluster } & probability \\
\hline US elections & $\begin{array}{l}\text { obama, president, republican, } \\
\text { democrats, house }\end{array}$ & \multirow[t]{2}{*}{1} & \multirow[t]{2}{*}{ politics \& elections } & \multirow[t]{2}{*}{.09} \\
\hline $\begin{array}{l}\text { Australian } \\
\text { climate politics }\end{array}$ & $\begin{array}{l}\text { australia, australian, abbott, } \\
\text { party, minister }\end{array}$ & & & \\
\hline $\begin{array}{l}\text { education \& } \\
\text { society }\end{array}$ & $\begin{array}{l}\text { education, social, student, } \\
\text { school, economic }\end{array}$ & 2 & education \& society & .03 \\
\hline $\begin{array}{l}\text { US climate } \\
\text { regulation }\end{array}$ & $\begin{array}{l}\text { tax, government, law, federal, } \\
\text { state }\end{array}$ & \multirow[t]{2}{*}{3} & \multirow[t]{2}{*}{ climate regulation } & \multirow[t]{2}{*}{.07} \\
\hline oil industry & $\begin{array}{l}\text { oil, company, drill, pipeline, } \\
\text { car }\end{array}$ & & & \\
\hline $\begin{array}{l}\text { climate change } \\
\text { impacts on } \\
\text { agricultural } \\
\text { production }\end{array}$ & $\begin{array}{l}\text { food, water, crop, population, } \\
\text { study }\end{array}$ & \multirow[t]{2}{*}{4} & \multirow[t]{2}{*}{ ecology } & \multirow[t]{2}{*}{.06} \\
\hline $\begin{array}{l}\text { wildlife } \\
\text { protection }\end{array}$ & $\begin{array}{l}\text { wwf, conservation, wildlife, } \\
\text { specie, coral }\end{array}$ & & & \\
\hline $\begin{array}{l}\text { energy } \\
\text { production }\end{array}$ & $\begin{array}{l}\text { energy, power, nuclear, coal, } \\
\text { electricity }\end{array}$ & \multirow[t]{2}{*}{5} & \multirow[t]{2}{*}{$\begin{array}{l}\text { economy/economic / energy } \\
\text { policy }\end{array}$} & \multirow[t]{2}{*}{.09} \\
\hline $\begin{array}{l}\text { government } \\
\text { budget }\end{array}$ & $\begin{array}{l}\text { market, income, cost, } \\
\text { government, economic }\end{array}$ & & & \\
\hline $\begin{array}{l}\text { general climate } \\
\text { change } \\
\text { skepticism }\end{array}$ & $\begin{array}{l}\text { chart, warm, empirical, trend, } \\
\text { global }\end{array}$ & \multirow[t]{2}{*}{6} & \multirow[t]{2}{*}{$\begin{array}{l}\text { discussion of the occurence } \\
\text { of climate change }\end{array}$} & \multirow[t]{2}{*}{.06} \\
\hline $\begin{array}{l}\text { temperature } \\
\text { measurement }\end{array}$ & $\begin{array}{l}\text { station, trend, record, figure, } \\
\text { adjustment }\end{array}$ & & & \\
\hline $\begin{array}{l}\text { occurance of } \\
\text { global warming }\end{array}$ & $\begin{array}{l}\text { global, level, increase, human, } \\
\text { year }\end{array}$ & \multirow[t]{2}{*}{7} & \multirow[t]{2}{*}{$\begin{array}{l}\text { temperature and weather } \\
\text { changes }\end{array}$} & \multirow[t]{2}{*}{.23} \\
\hline $\begin{array}{l}\text { models of past } \\
\text { temperature } \\
\text { changes }\end{array}$ & $\begin{array}{l}\text { model, temperature, period, } \\
\text { surface, cycle }\end{array}$ & & & \\
\hline
\end{tabular}




\begin{tabular}{|c|c|c|c|c|}
\hline extreme weather & $\begin{array}{l}\text { cold, winter, year, snow, } \\
\text { warm }\end{array}$ & & & \\
\hline $\begin{array}{l}\text { greenhouse gas } \\
\text { emissions }\end{array}$ & $\begin{array}{l}\text { co2, carbon, dioxide, } \\
\text { atmosphere, warm }\end{array}$ & \multirow[t]{4}{*}{8} & \multirow{4}{*}{$\begin{array}{l}\text { (discussion of) } \\
\text { causes/explanations of } \\
\text { climate change }\end{array}$} & \multirow[t]{4}{*}{.08} \\
\hline $\begin{array}{l}\text { general doubt of } \\
\text { climate scientific } \\
\text { explanations }\end{array}$ & $\begin{array}{l}\text { temperature, anomaly, } \\
\text { month, global, science }\end{array}$ & & & \\
\hline cosmic radiation & $\begin{array}{l}\text { solar, sun, earth, cloud, } \\
\text { cosmic }\end{array}$ & & & \\
\hline melting ice & ice, sea, arctic, melt, glacier & & & \\
\hline $\begin{array}{l}\text { discrediting } \\
\text { climate science }\end{array}$ & $\begin{array}{l}\text { gore, real, warm, truth, } \\
\text { climategate }\end{array}$ & \multirow[t]{4}{*}{9} & \multirow[t]{4}{*}{ questioning climate science } & \multirow[t]{4}{*}{.12} \\
\hline $\begin{array}{l}\text { questioning } \\
\text { advocate claims }\end{array}$ & $\begin{array}{l}\text { wuwt, climatic, watts, } \\
\text { anthony, oscillation }\end{array}$ & & & \\
\hline $\begin{array}{l}\text { challenging } \\
\text { climate science }\end{array}$ & $\begin{array}{l}\text { paper, climate, claim, } \\
\text { scientific, evidence }\end{array}$ & & & \\
\hline $\begin{array}{l}\text { questioning the } \\
\text { interpretation of } \\
\text { climate data }\end{array}$ & $\begin{array}{l}\text { climate, temperature, co2, } \\
\text { modern, period }\end{array}$ & & & \\
\hline $\begin{array}{l}\text { extreme weather } \\
\text { events }\end{array}$ & $\begin{array}{l}\text { storm, hurricane, weather, } \\
\text { extreme, flood }\end{array}$ & \multirow[t]{2}{*}{10} & \multirow[t]{2}{*}{ impact of climate change } & \multirow[t]{2}{*}{.04} \\
\hline $\begin{array}{l}\text { climate change } \\
\text { impact }\end{array}$ & $\begin{array}{l}\text { published, climate, central, } \\
\text { read, researching }\end{array}$ & & & \\
\hline $\begin{array}{l}\text { climate change } \\
\text { research } \\
\text { institutions and } \\
\text { members }\end{array}$ & $\begin{array}{l}\text { research, policy, program, } \\
\text { international, university }\end{array}$ & \multirow[t]{2}{*}{11} & \multirow[t]{2}{*}{$\begin{array}{l}\text { (criticism of) climate change } \\
\text { research institutions and } \\
\text { members }\end{array}$} & \multirow[t]{2}{*}{.13} \\
\hline $\begin{array}{l}\text { criticism of } \\
\text { climate change } \\
\text { research } \\
\text { institutions }\end{array}$ & $\begin{array}{l}\text { scientist, climate, science, } \\
\text { ipcc, global }\end{array}$ & & & \\
\hline
\end{tabular}




\section{Goodness of fit statistics ERGMs}

\section{First Model:}

Dyad-wise shared partners

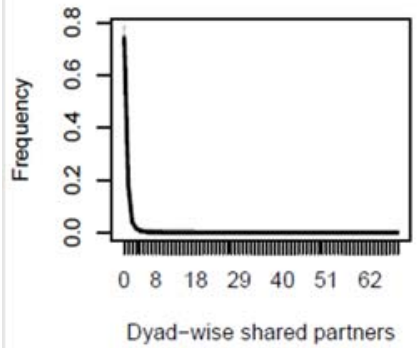

Indegree

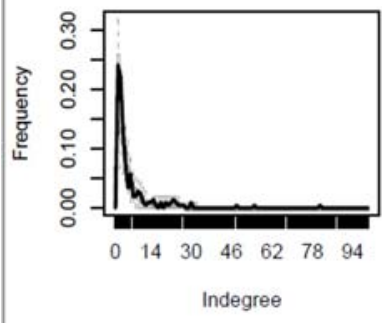

Second Model

Dyad-wise shared partners
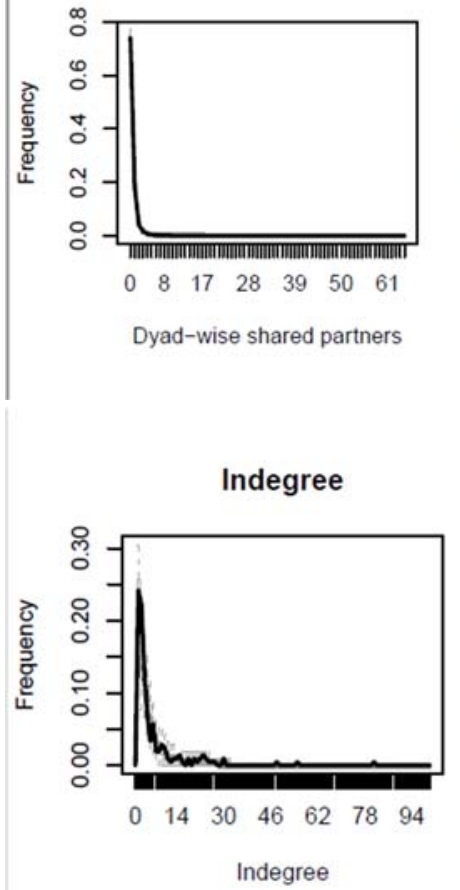

Edge-wise shared partners

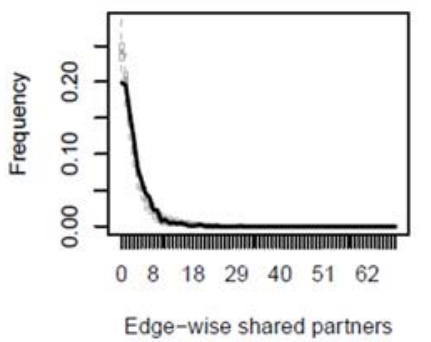

Geodesic distances

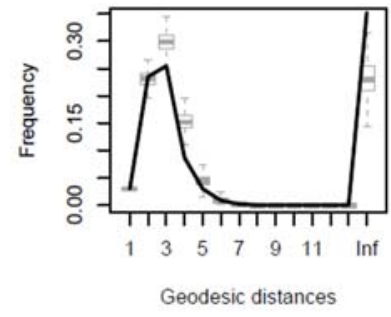

Edge-wise shared partners

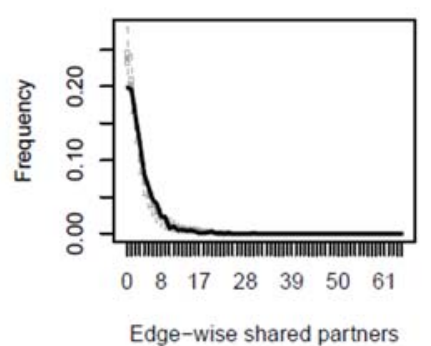

Geodesic distances

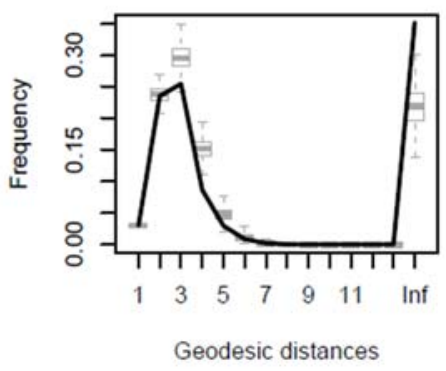

Degree

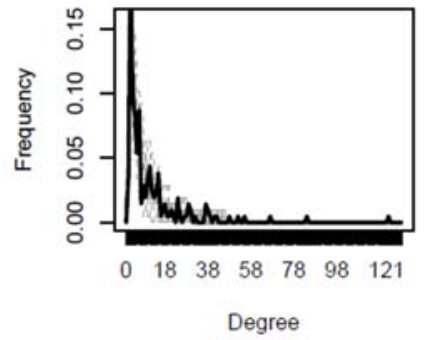

Degree

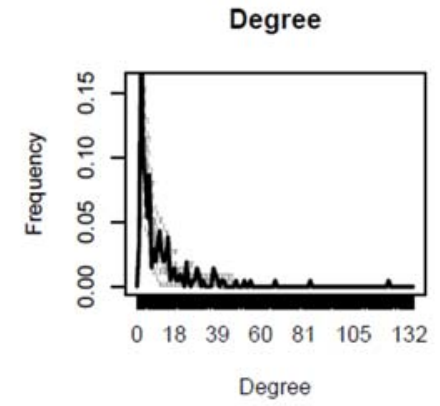


Third model:

Dyad-wise shared partners

Edge-wise shared partners

Degree
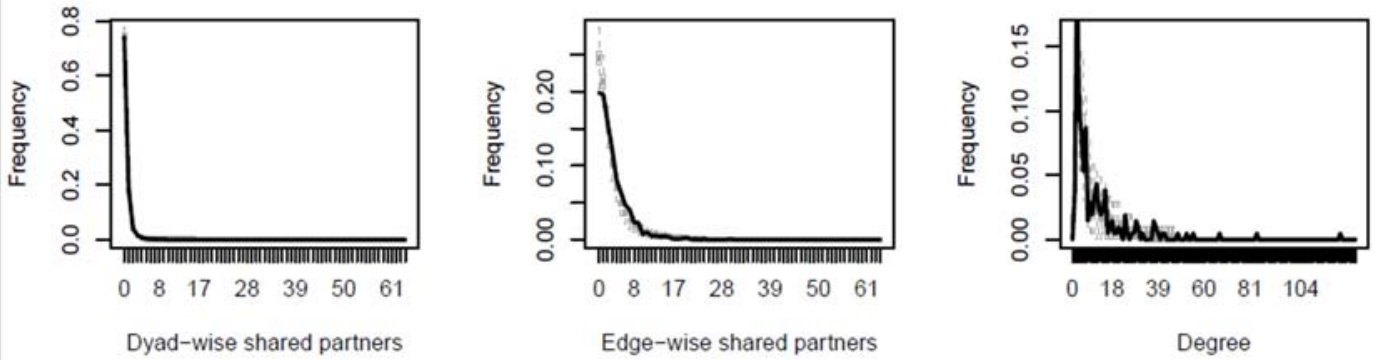

Indegree

Geodesic distances
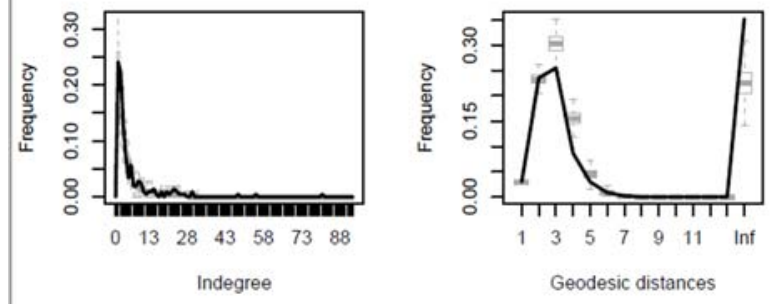


\section{References}

Ackland, R. (2005). Mapping the U.S. political blogosphere: Are conservative bloggers more prominent? Australian National University, ANU Research Publications. Available online: https://openresearchrepository.anu.edu.au/handle/1885/45827

Ackland, R. (2013). Web social science. Concepts, data and tools for social scientists in the digital age. London: Sage Publications

Ackland, R. \& O'Neil, M. (2011). Online collective identity: The case of the environmental movement. Social Networks, 33, 177-190.

Ackland, R. \& Shorish, J. (2014). Political homophily on the web. In M. Cantijoch, R. Gibson, \& S. Ward (Eds.), Analysing social media data and web networks (pp. 2546). Houndmills, UK / New York, NY: Palgrave Macmillan.

Adamic, L. \& Glance, N. (2005). The political blogosphere and the 2004 US election: divided they blog. Paper presented at the Proceedings of the 3rd international workshop on Link discovery.

Anderegg, W. R. L. (2010). Moving beyond scientific agreement. Climatic Change, 101, 331-337.

Antal, T., Krapivsky, P. L. \& Redner, S. (2006). Social balance on networks: The dynamics of friendship and enmity. Physica D, 224, 130-136.

Atouba, Y. C. \& Shumate, M. (2015). International nonprofit collaboration: Examining the role of homophily. Nonprofit and Voluntary Sector Quarterly, 44(3), 587-608.

Bae, S. \& Choi, J. (2000). Cyberlinks between human rights NGOs: a network analysis, 58th Annual National Meeting of the Midwest Political Science Association, Chicago, IL, pp.27-30, April 2000.

Baldassari, D. \& Diani, M. (2007). The integrative power of civic networks. American Journal of Sociology, 113, 735-780.

Barabási, A. L. \& Albert, R. (1999). Emergence of scaling in random networks. Science, 286(5439), 509-512.

Barabási, A. L., Albert, R. \& Jeong, H. (2000). Scale-free characteristics of random networks: the topology of the world wide web. Physica A, 281, 69-77.

Barnett, G. A. \& Park, H. W. (2005). The structure of international internet hyperlinks and bilateral bandwidth. Annales Des Télécommunications, 60(9-10), 1110-1127.

Benkler, Y., Roberts, H., Faris, R., Solow-Niederman, A. \& Etling, B. (2015). Social Mobilization and the Networked Public Sphere: Mapping the SOPA-PIPA Debate. Political Communication, 32(4), 594-624.

Blei, D. M. (2012). Probabilistic topic models. Communications of the ACM, 55(4), 77-84.

Blei, D. M., Ng, A. Y., \& Jordan, M. I. (2003). Latent dirichlet allocation. The Journal of Machine Learning Research, 3, 993-1022.

Brin, S. \& Page, L. (1998). The anatomy of a large-scale hypertextual web search engine. Computer Networks and ISDN Systems, 30, 107-117.

Collins, H. (2014). Rejecting knowledge claims inside and outside science. Social Studies of Science, 44(5), 722-735. 
Cook, J., Nuccitelli, D., Green, S. A., Richardson, M., Winkler, B., Painting, R., Way, R., Jacobs, P., Skuce, A. (2013). Quantifying the consensus on anthropogenic global warming in the scientific literature. Environmental Research Letters, 8, 1-7.

Cranmer, S. J., Desmarais, B. A. \& Menninga, E. J. (2012). Complex dependencies in the alliance network. Conflict Management and Peace Science, 29(3), 279-313.

Davenport, E. \& Cronin, B. (2000). The citation network as a prototype for representing trust in virtual environments. In B. Cronin \& H. Atkins (Eds.), The Web of Knowledge: A Festschrift in Honor of Eugene Garfield. Information Today, Metford, NJ.

de Maeyer, J. (2013). Towards a hyperlinked society: A critical review of link studies. New Media \& Society, 15(5), 737-751.

Dunlap, R. E. \& McCright, A. M. (2011). Organized climate change denial. In J. S. Dryzek, R. B. Norgaard \& D. Schlosberg (Eds.), The Oxford Handbook of Climate Change and Society (pp. 144-160). Oxford: Oxford University Press.

Elgesem, D., Steskal, L. \& Diakopoulos, N. (2015). Structure and content of the discourse on climate change in the blogosphere: The big picture. Environmental Communication: A Journal of Nature and Culture, 9, 169-188.

Elgin, D. J. (2015). Utilizing hyperlink network analysis to examine climate change supporters and opponents. Review of Policy Research, 32(2), 226-245.

Foot, K., Schneider, S. M., Dougherty, M., Xenos, M. \& Larsen, E. (2003). Analyzing linking practices: Candidate sites in the 2002 US electoral Web sphere. Journal of Computer-Mediated Communication, 8(4), 0-0.

Fu, S. J. \& Shumate, M. (2016). Hyperlinks as institutionalized connective public goods for collective action online. Journal of Computer-Mediated Communication, 21, 298-311.

Gibson, D., Kleinberg, J. \& Raghavan, P. (1998). Inferring web communities from link topology. Proceedings from the Ninth ACM Conference on Hypertext and Hypermedia.

González-Bailón, S. (2009a). Opening the black-box of link formation: Social factors underlying the structure of the web. Social Networks, 31, 271-280.

González-Bailón, S. (2009b). Traps on the Web. The impact of economic resources and traditional news media on online traffic flow. Information, Communication \& Society, 12(8), 1149-1173.

González-Bailón, S. \& Wang, N. (2016). Networked discontent: The anatomy of protest campaigns in social media. Social Networks, 44, 95-104.

Häussler, T., Adam, S., Schmid-Petri, H. \& Reber, U. (2017). How Political Conflict Shapes Online Spaces: A Comparison of Climate Change Hyperlink Networks in the U.S. and Germany. International Journal of Communication, 11, 3096-3117.

Hargittai, E., Gallo, J., \& Kane, M. (2008). Cross-ideological discussions among conservative and liberal bloggers. Public Choice, 134(1-2), 67-86.

Hindman, M., Tsioutsiouliklis, K. \& Johnson, A. (2003). Googlearchy: How a few heavily linked sites dominate politics online. Paper presented at the Annual Meeting of the Midwest Political Science Association. 
Holland, P. W. \& Leinhardt, S. (1976). Local structure in social networks. Sociological methodology, 7(1), 1-45.

Hummon, N. P. \& Doreian, P. (2003). Some dynamics of social balance processes: bringing Heider back into balance theory. Social Networks, 25, 17-49.

Kaiser, J., Rhomberg, M., Maireder, A. \& Schlögl, S. (2016). Energiewende's lone warriors: A hyperlink network analysis of the German Energy Transition Discourse. Media and Communication, 4(4), 18-29.

Kleinberg, J. (1999). Authoritative sources in a hyperlinked environment. Journal of the $A C M, 46(5), 604-632$.

Kossinets, G. \& Watts, D. J. (2009). Origins of homophily in an evolving social network. American Journal of Sociology, 115, 405-450.

Kriesi, H. (2004). Strategic political communication: mobilizing public opinion in ,audience democracies'. In F. Esser \& B. Pfetsch (Eds.), Comparing political communication. Theories, cases, and challenges (pp. 184-212). Cambridge: Cambridge University Press.

Lusher, D. \& Ackland, R. (2011). A relational hyperlink analysis of an online social movement. Journal of Social Structure, 12 (4), Available online: http://www.cmu.edu/joss/content/articles/volume12/Lusher/.

Leifeld, P., Cranmer, S.J. \& Desmarais, B. A. (2017). xergm. Extensions for Exponential Random Graph Models. R package version 1.8.2.

Lusher, D., Koskinen, J. \& Robins, G. (2013). Exponential Random Graph Models for Social Networks. Cambridge University Press, New York.

Maier, D., Waldherr, A., Miltner, P., Jähnichen, P. \& Pfetsch, B. (2017a). Exploring issues in a networked public sphere: Combining hyperlink network analysis and topic modeling. Social Science Computer Review. Advance online publication. doi: 10.1177/0894439317690337

Maier, D., Waldherr, A., Miltner, P., Wiedemann, G., Niekler, A., Heyer, G., Keinert, A., Pfetsch, B., Häussler, T., Reber, U., Schmid-Petri, H., \& Adam, S. (2017b). Applying LDA Topic Modeling in Communication Research: Towards a Valid and Reliable Methodology. Paper presented at the annual conference of the International Communication Association (ICA), San Diego.

Marlow, C. (2004). Audience, structure and authority in the weblog community. Paper presented at the Conference of the International Communication Association (ICA), New Orleans. Available at: http://rockngo.org/wpcontent/uploads/mt/archives/ICA2004.pdf

McNutt, K. \& Marchildon, G. (2009). Think tanks and the web: Measuring visibility and influence. Canadian Public Policy, 35(2), 219-236.

McPherson, M., Smith-Lovin, L. \& Cook, J. (2001). Birds of a feather: homophily in social networks. Annual Review of Sociology, 27, 415-444.

Monge, P. R. \& Contractor, N. S. (2003). Theories of communication networks. New York: Oxford University Press. 
Niekler, A. \& Jähnichen, P. (2012). Matching Results of Latent Dirichlet Allocation for Text. Proceedings of ICCM 2012, 11th International Conference on Cognitive Modeling, Universitätsverlag der TU Berlin, 317-322.

O’Neil, M. \& Ackland, R. (2006). The structural role of nanotechnology - opposition in online environmental-activist networks. Paper presented to 26th International Sunbelt Social Network Conference, Vancouver.

Painter, J. \& Gavin, N. T. (2015). Climate skepticism in British newspapers, 2007-2011. Environmental Communication. Epub ahead of print 27 January 2015. DOI:10.1080/17524032.2014.995193

Page, L., Brin, S., Motwani, R. \& Winograd, T. (1999). The PageRank citation ranking: bringing order to the web. Available online: http://ilpubs.stanford.edu:8090/422/1/1999-66.pdf

Park, H. W. (2003). Hyperlink network analysis: A method for the study of social structure on the web. Connections, 25(1), 49-61.

Park, H.W., Kim, C.S. \& Barnett, G.A. (2004). Socio-communicational structure among political actors on the Web in South Korea: the dynamics of digital presence in cyberspace. New Media and Society, 6(3), 403-423.

Park, H. W., Barnett, G. A. \& Chung, C. J. (2011). Structural changes in the 2003-2009 global hyperlink network. Global Networks, 11(4), 522-542.

Park, H.W., Kim, C.S. \& Barnett, G.A. (2004). Socio-communicational structure among political actors on the Web in South Korea: the dynamics of digital presence in cyberspace. New Media and Society, 6(3), 403-423.

Pilny, A., \& Shumate, M. (2012). Hyperlinks as extensions of offline instrumental collective action. Information, Communication \& Society, 15(2), 260-286.

Robins, G., Pattison, P., Kalish, Y. \& Lusher, D. (2007). An introduction to exponential random graph ( $\left.{ }^{*}\right)$ models for social networks. Social Networks, 29(2), 173-191.

Robins, G., Pattison, P. \& Wang, P. (2009). Closure, connectivity and degree distributions: Exponential random graph ( $\left.\mathrm{p}^{*}\right)$ models for directed social networks. Social Networks, 31(2), 105-117.

Rogers, R. \& Ben-David, A. (2008). The Palestinian-Israeli peace process and transnational issue networks: the complicated place of the Israeli NGO. New Media \& Society, 10(1), 41-72.

Rogers, R. \& Marres, N. (2000). Landscaping climate change: a mapping technique for understanding science and technology debates on the World Wide Web. Public Understanding of Science, 9(2), 141-163.

Schäfer, M. (2012). Online communication on climate change and climate politics: a literature review. WIREs Clim Change, 3, 527-543.

Shapiro, M. A. \& Park, H. W. (2015). More than entertainment: YouTube and public responses to the science of global warming and climate change. Social Science Information, 54(1), 115-145.

Shumate, M. \& Dewitt, L. (2008). The north/south divide in NGO hyperlink networks. Journal of Computer-Mediated Communication, 13(2), 405-428. 
Shumate, M. \& Lipp, J. (2008). Connective collective action online: An examination of the hyperlink network structure of an NGO issue network. Journal of ComputerMediated Communication, 14(1), 178-201.

Shumate, M. \& Palazzolo, E. T. (2010). Exponential Random Graph ( $\mathrm{p}^{*}$ ) models as a method for social network analysis in communication research, Communication Methods and Measures, 4(4), 341-371.

Snijders, T. A. B., van de Bunt, G. G. \& Steglich, C.E.G. (2010). Introduction to stochastic actor-based models for network dynamics. Social Networks, 32, 44-60.

Sunstein, C. (2001). Republic.com. Princeton: Princeton University Press.

Thelwall, M., 2006. Interpreting social science link analysis: a theoretical framework. Journal of the American Society for Information Science and Technology, 57(1), 60-68.

Tremayne, M. (2004). The web of context: Applying network theory to the use of hyperlinks in journalism on the Web. Journalism \& Mass Communication Quarterly, 81, 237-253.

Waldherr, A., Maier, D., Miltner, P., \& Günther, E. (2017). Big data, big noise: The challenge of finding issue networks on the web. Social Science Computer Review, 35(4), 427-443. 